\title{
Different Effects of Aerobic Exercise and Diaphragmatic Breathing on Lower Esophageal Sphincter Pressure and Quality of Life in Patients with Reflux: A Comparative Study
}

\author{
Mehdi Ahmadi ${ }^{1}$, Mohsen Amiri ${ }^{2}$, Tahere Rezaeian ${ }^{1}$, Iraj Abdollahi ${ }^{2, *}$, Amir Mansour Rezadoost ${ }^{3}$, \\ Masoudreza Sohrabi ${ }^{4}$, Enayatollah Bakhshi ${ }^{5}$
}

1. PhD in Physiotherapy, Department of Physiotherapy, University of Social Welfare and Rehabilitation Sciences, Tehran, Iran

2. Assosiate Professor in Physiotherapy, Department of Physiotherapy, University of Social Welfare and Rehabilitation Sciences, Tehran, Iran

3. Assistant Professor, Internal Medicine, Tehran University of Medical Sciences, Tehran, Iran

4. Gastrointestinal and Liver Disease Research Center (GILDRC), Iran University of Medical Sciences, Tehran, Iran

5. Professor, Department of Biostatistics and Epidemiology, University of Social Welfare and Rehabilitation Sciences, Tehran, Iran

\section{* Corresponding Author:}

Iraj Abdollahi

Assosiated Professor in Physiotherapy, Department of Physiotherapy, University of Social Welfare and Rehabilitation Sciences, Tehran, Iran

Tel: + 982122180039

Fax: + 982122180039

Email: irajabdollahi@hotmail.com

Received: 30 Jul. 2020

Accepted: 11 Dec. 2020

\section{ABSTRACT}

\section{BACKGROUND}

Gastroesophageal reflux disease (GERD) is a worldwide disorder with an increasing prevalence. The quality of life (QOL) of the patients may be influenced by reflux disease. Diaphragmatic breathing (DB), as well as aerobic exercise (AE), may improve the symptoms of reflux disease, although it remains a controversial issue. The aim of this study was to compare the effects of AE and DB on QOL and lower esophageal sphincter (LES) pressure of patients with moderate to severe reflux.

\section{METHODS}

This was a case-control study that was conducted for 8 weeks among patients with moderate to severe GERD. The block randomization method was designed to randomize patients into three groups (AE, DB, and control) to achieve equal sample sizes. The control group received omeprazole $20 \mathrm{mg}$ once daily. The other groups, in addition to omeprazole, received AE and DB. QOL and LES pressure were measured before and after the study by Questionary and Manometry method, respectively.

\section{RESULTS}

75 patients were enrolled in this study. Positive effects of DB on LES pressure was approved $(p=0.001)$. DB had significantly more effects on QOL than aerobic exercise ( $\mathrm{p}=$ $0.003)$. AE can significantly improve QOL in patients $(p=0.02)$ but no significant change in LES pressure $(p=0.38)$. There was no change in the control group for both variables.

\section{CONCLUSION}

AE had no effects on LES pressure but can improve QOL of the patients. DB had more effects on QOL than AE, so injured or disable patients with reflux who cannot do $\mathrm{AE}$, can benefit from DB to improve their reflux symptoms.

\section{KEYWORDS:}

Reflux, Manometry, Diaphragmatic breathing, Aerobic exercise, Quality of life, LES

\section{Please cite this paper as:}

Ahmadi M, Amiri M, Rezaeian T, Abdollahi I, Rezadoost AM, Sohrabi MR, Bakhshi E. Different Effects of Aerobic Exercise and Diaphragmatic Breathing on Lower Esophageal Sphincter Pressure and Quality of Life in Patients with Reflux: A Comparative Study. Middle East J Dig Dis 2021;13:61-66. doi: 10.34172/mejdd.2021.205. 


\section{INTRODUCTION}

Gastroesophageal reflux disease (GERD) is a common disorder worldwide with an increasing trend. ${ }^{1}$ According to the Montreal definition of GERD, it is "a condition which develops when the reflux of stomach contents causes symptoms". ${ }^{2}$ Approximately one-quarter of people living in Western countries have experienced GERD. ${ }^{3}$ In the epidemiological studies conducted in Iran so far, a very wide range of prevalence has been reported for GERD, and also reflux has increased over the last two decades. ${ }^{4}$ Heartburn and regurgitation are the most frequent symptoms of reflux, and also, dysphagia, chest pain, chronic cough, laryngitis, and asthma may be present. ${ }^{5}$ The main underlying causal mechanism of GERD constitutes a failure in the valvular mechanism of the lower esophageal sphincter (LES), which normally prevents the return of stomach contents to the esophagus. The diaphragm muscle, the abdominal part of the esophagus, and the acute angle of His are the main structures of the antireflux barrier. ${ }^{6}$ LES pressure plays a vital role in reflux control, as assessed by the esophageal manometry method. ${ }^{7}$ On the other hand, proton pump inhibitors (PPIs) are the first step and effective in preventing complications of GERD. ${ }^{8}$ PPIs have many side effects on the body, and about $40 \%$ of patients experienced refractory GERD and have resistant symptoms. ${ }^{9}$ While laparoscopic anti-reflux surgery (LARS) is the common way for PPI-refractory GERD ${ }^{10}$ patients prefer less invasive anti-reflux treatment. ${ }^{11}$ So, it is necessary to use less invasive, available, and simple intervention to decrease GERD symptoms and improve the quality of life (QOL) of the patients. ${ }^{12} \mathrm{DB}$ exercise by activating the diaphragm muscle can reduce reflux symptoms. ${ }^{13}$ Some studies evaluated the effects of $\mathrm{AE}$ on the symptom of reflux and found contradictory results. High-level AE induced reflux in athletes because the LES resting pressure was decreased. ${ }^{14}$ Also, Bilski suggested that moderate AE had a positive effect on the gastrointestinal tract and may decrease reflux. ${ }^{15}$ Other studies conclude that moderate $\mathrm{AE}$ has no influence on reflux. ${ }^{16,17}$ So, the aim of this study was to compare the effects of $\mathrm{AE}$ and DB on LES pressure and QOL of patients with reflux.

\section{MATERIALS AND METHODS}

\section{Patient Selection}

The study started when consecutive patients attending Taleghani Hospital were invited to join after fulfilling inclusion criteria. The study design was before and after with the control group (ethics code: USWR.REC.1396.272). Participants (18 to 50 years old) were included if they had moderate to severe GERD, according to the assessment of clinical severity by Kahrilas definition. ${ }^{18}$ Furthermore, patients with stable cardiovascular and respiratory system were considered to be included. Exclusion criteria were alcohol and tobacco use, pregnancy, patients with extreme body mass index $(<18$ or $>35)$, or surgery involving the gastrointestinal tract because these may alter the anatomy and physiology of the esophagus and stomach. Informed consent was obtained from all participants, and the protocol was approved by the Singhealth Centralised Institutional Review Board before the start of the study.

All participants were matched according to age, sex, and demographic characteristics. The block randomization method was designed to randomize 75 patients into three groups that resulted in equal sample sizes. In the control group, omeprazole (capsule $20 \mathrm{mg}$, KRKA, Slovenia), before breakfast and daily, was used by the participants. In the DB group, in addition to omeprazole, DB was performed, and in the $\mathrm{AE}$ group, in addition to omeprazole, AE program was used. The study was performed for 8 weeks, and the patients in each group received their interventions during this period. Researchers contacted the patients through phone calls as well as the traditional faceto-face clinical program. All patients completed the study.

\section{Esophageal Manometry}

The esophageal manometric procedure was performed by a gastrointestinal specialist in a way that was described by Spechler. ${ }^{19}$ This procedure (using the Sierra system [Duluth, GA, USA]) was performed with volunteers in the supine position and after at least 6 hours of fasting. The probe had 36 pressure $1 \mathrm{~cm}$ apart and 18 impedance sensors $2 \mathrm{~cm}$ apart. Pressure calibration was performed at 0 and $300 \mathrm{mmHg}$ and zeroed to atmospheric pressure before the procedure. The probe was positioned through one nostril with at least five sensors distal to the diaphragm. The motility catheter was passed through the nose or 


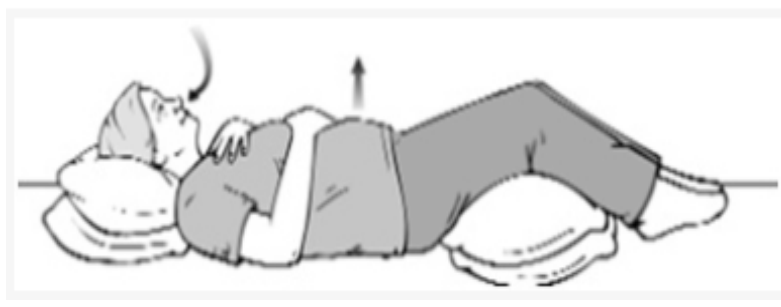

Fig.1: How to do diaphragmatic breathing exercise

mouth until the pressure sensors were positioned in the stomach and while the patient breathed quietly. LES pressure was measured as the mid respiratory level in the area of maximal pressure.

\section{Quality of Life Quetionary}

All patients were given Quality Of Life in Reflux and Dyspepsia Questionary (QOLRAD) at baseline, at the end of the treatment for DB, AE, and control group. This questionary was translated to the Persian language and had good validity. We evaluated the total score to suggest the QOL; the higher score means a better quality of life. ${ }^{20}$

\section{Diaphragmatic Breathing Exercises (DB)}

DB was performed five days a week and five sessions each day. Each session consisted of 75 respiration. The patient is lying in the supine position and placing a pillow under his knees, putting one hand on his chest and placing the other on the abdomen and maintaining his or her contact with the body. The patient inhales a deep breath through his nose, as much as the abdominal hand reaches the highest point of the earth. Then, he takes out air through his mouth and returns to the first (Figure 1).

\section{Aerobic Exercises (AE)}

First, the maximum heart rate was recorded for each person [maximum age-related heart rate is achieved by subtracting age from 220 (beat per minute)]. For moderateintensity physical activity, the target heart rate should be about $70 \%$ of the maximum heart rate. ${ }^{21}$ Participants run with $70 \%$ of maximum heart rate for about 20 minutes for each session. Patients received this program five sessions a week during the study.

\section{Statistical Analysis}

The study was initially designed to compare the efficacy of $\mathrm{AE}$ on the QOL and LES pressure versus DB. However, early into the study, it was noted that most patients recruited had moderate to severe reflux, and the study protocol was amended with the new aim to compare QOL and LES pressure of post-DB patients with $\mathrm{AE}$ in all patients. All authors had access to the study data and reviewed and approved the final manuscript. Kolmogorov-Smirnov test was utilized to assess normality by SPSS version 23. Differences in outcomes between two groups were analyzed with ANOVA and ANCOVA; respectively. paired t test was used for considerable differences within groups. Variables were analyzed while the level of significance was set at $p<0.05$.

\section{RESULTS}

\section{Patient Characteristics}

A pilot study was first performed on eight patients with reflux. Twenty subjects in each group was calculated with a test type I error 0.05 and test type II error 0.20 , by using the software PASS 11.

Seventy-five participants were enrolled and were randomly allocated to three groups. The mean age in AE group was $37.00 \pm 9.25$ years and in the DB group was 42.62 \pm 8.20 years. Furthermore, the control group consisted of 13 women with mean age of $40.31 \pm 6.88$ years. The initial 50 patients underwent DB and AE immediately on enrolment (treatment groups), whereas the subsequent 25 patients were considered as the control group. There was no significant difference in terms of demographic characteristics between the groups (Table1).

\section{Esophageal manometry}

There was no significant difference in the LES manometry before the study between the groups ( $p=$ $0.19)$. DB had significantly positive effects on LES pressure $(p=0.001)$. No significant change in LES pressure was seen in AE group $(p=0.38)$. There was no change in LES pressure in the control group (Table 2).

\section{QoL Score}

There was no significant difference in the QOL before the study between the groups $(p=0.13)$. DB had significantly more effects on QOL than $\mathrm{AE}(p=0.003)$. AE could significantly improve the QOL of the patients ( $p=$ 0.02). There was no change in QOL in the control group (Table 2). 
Table 1: Demographic data of the subjects (Mean SD)

\begin{tabular}{|c|c|c|c|c|}
\hline \multirow[t]{2}{*}{ Variables } & \multicolumn{3}{|c|}{ Groups } & \multirow[t]{2}{*}{$p$ value* } \\
\hline & Aerobic $(n=25)$ & Breathing $(n=25)$ & Control $(n=25)$ & \\
\hline Age (years)\# & $37.00 \pm 9.25$ & $42.62 \pm 8.20$ & $40.31 \pm 6.88$ & $0.06^{*}$ \\
\hline Weight (kg) & $79.20 \pm 6.56$ & $74.52 \pm 3.14$ & $75.11 \pm 4.23$ & $0.84 *$ \\
\hline Height (m) & $1.81 \pm 0.21$ & $1.78 \pm 0.36$ & $1.79 \pm 0.45$ & $0.33^{*}$ \\
\hline $\operatorname{BMI}\left(\mathrm{Kg} / \mathrm{m}^{2}\right)$ & $24.22 \pm 1.33$ & $23.58 \pm 2.12$ & $23.43 \pm 3.14$ & $0.20^{*}$ \\
\hline Sex\#\# & $13(52 \%)$ & $11(44 \%)$ & $13(52 \%)$ & $0.1 * *$ \\
\hline
\end{tabular}

Table 2: Comparison of quality of life and LES pressure between subjects of the two experimental groups in different phases.

\begin{tabular}{|c|c|c|c|c|c|c|c|}
\hline \multirow{3}{*}{ Variable } & \multirow{3}{*}{ Number } & \multirow{3}{*}{ Time-point } & \multicolumn{3}{|c|}{ Group } & \multirow{3}{*}{$\mathbf{F}$} & \multirow{3}{*}{$p$ value } \\
\hline & & & Control & Breathing & Aerobic & & \\
\hline & & & Mean \pm SD & Mean \pm SD & Mean \pm SD & & \\
\hline \multirow{2}{*}{$\begin{array}{l}\text { Quality of life } \\
\text { (QOLRAD Score) }\end{array}$} & \multirow{2}{*}{25} & Before & $3.01 \pm 0.45$ & $3.42 \pm 0.48$ & $3.41 \pm 0.7$ & 2.08 & $0.13 *$ \\
\hline & & After & $3.18 \pm 0.66$ & $4.56 \pm 0.55$ & $3.99 \pm 0.9$ & 18.36 & $0.001 * *$ \\
\hline \multirow{2}{*}{$\begin{array}{l}\text { LES pressure } \\
(\mathrm{Mm}, \mathrm{Hg})\end{array}$} & \multirow{2}{*}{25} & Before & $20.3 \pm 7.42$ & $16.6 \pm 6.29$ & $18.4 \pm 4.7$ & 1.70 & $0.19^{*}$ \\
\hline & & After & $17.15 \pm 4.74$ & $24.3 \pm 4.61$ & $19.9 \pm 6.46$ & 9.11 & $0.001 * *$ \\
\hline
\end{tabular}

*ANOVA

**ANCOVA

\section{DISCUSSION}

Our study showed that in patients with moderate to severe GERD, standardized DB, and AE exercise training significantly improved the QOL of the patients, but this benefit was greater in DB group. Only DB significantly changed LES pressure. In the control group, we did not find any significant change in LES pressure and QOL.

We used two respiratory exercises (DB and AE) as an intervention because gastroesophageal reflux impairs pulmonary function, and reflux is a common disease in patients with asthma and chronic cough that decrease respiratory parameters and QOL. ${ }^{22}$ Pulmonary desease mortality is still increasing worldwide, which needs special attention. ${ }^{23}$ The importance of the diaphragm is recognized in maintaining the anti-reflux barrier at the LES. Abdominal breathing exercises have been shown to improve GERD symptoms. ${ }^{24}$ Because the diaphragm consists of striated muscle under voluntary contraction, patients theoretically can be taught how to control these contractions. In the present study, DB improved the QOLin patients with reflux, similar to what was reported in Ehere study. ${ }^{24}$ As well, Roman found that DB improved reflux symptoms and decreased the patients' need for PPIs. ${ }^{25}$

The other finding of the present study was that DB increased LES pressure that was the same as Carvalho study. They found that respiratory exercise could result in LES pressure enhancement. ${ }^{26}$

Studies that focused on the effects of PPIs on the reflux symptom showed that omeprazole could improve the QOL of the patients, but the QOL of the control group in the present study did not significantly change. Maybe the normal dosage of PPIs should be $40 \mathrm{mg}$ daily to improve the QOL of the patients with reflux. ${ }^{27}$

The effects of AE to improve reflux symptoms have contradictory results. The main different aspect between these studies is the different exercise intensities: the more intensity, the more reflux. Submaximal and moderate exercise may have more positive effects on reflux symptoms. In the present study, aerobic exercise did not significantly change LES pressure, but Herregods, found that running decreased LES pressure. ${ }^{28}$ It is necessary to say that subjects in Herregods study ran on a treadmill for $30 \mathrm{~min}$ at $60 \%$ of maximum heart rate, followed by a short rest period and another 20-min period of running at $85 \%$ of maximum heart rate. Menedes and colleagues concluded that light or short sessions of physical activity had no influence on reflux symptoms, but in the present study, the QOL of the patients was significantly improved. ${ }^{17}$ In the present study, AE had positive effects on QOL without any significant change in LES pressure. Maybe change in mental aspects by AE 
improve the QOL of the patients. ${ }^{29}$ Finally, DB had more effects on QOL than $\mathrm{AE}$ so, the patients with reflux and some orthopedic problems who cannot perform $\mathrm{AE}$, can benefit from DB to improve their QOL.

\section{CONCLUSION}

DB improved both LES pressure and QOL of the patients with reflux. DB had more effects on QOL than AE, so injured or disabled patients with reflux who cannot perform AE can benefit from DB.

\section{ACKNOWLEDGMENTS}

Thanks to the Gastroenterology Clinic of Taleghani Hospital for referring patients with reflux and all the participants who made this study possible.

\section{Funding/Support}

This study was supported by the University of Social Welfare and Rehabilitation Sciences.

\section{Authors' Contribution}

Mehdi Ahmadi and Tahere Rezaeian participated in the design and data collection, and writing of the manuscript. Iraj Abdollahi and Mohsen Amiri were supervisors. Amir Mansoor Rezadoost and Masoud Reza Sohrabi consultant the study and performed esophagus manometry. Enayatollah Bakhshi participated in the statistical analysis.

\section{ETHICAL APPROVAL}

There is nothing to be declared.

\section{CONFLICT OF INTEREST}

The authors declare no conflict of interest related to this work.

\section{REFERENCES}

1. Bredenoord AJ, Pandolfino JE, Smout AJ. Gastrooesophageal reflux disease. Lancet 2013;381:1933-42. doi: 10.1016/S0140-6736(12)62171-0.

2. Vakil N, van Zanten SV, Kahrilas P, Dent J, Jones R. The Montreal definition and classification of gastroesophageal reflux disease: a global evidence-based consensus. Am J Gastroenterol 2006;101:1900-20; quiz 43. doi: 10.1111/j.1572-0241.2006.00630.x.

3. MacFarlane B. Management of gastroesophageal reflux disease in adults: a pharmacist's perspective. Integr
Pharm Res Pract 2018;7:41-52. doi: 10.2147/IPRP. S142932.

4. Delavari A, Moradi G, Birjandi F, Elahi E, Saberifiroozi M. The Prevalence of Gastroesophageal Reflux Disease (GERD) in the Islamic Republic of Iran: A Systematic Review. Middle East J Dig Dis 2012;4:5-15.

5. Chen J, Brady P. Gastroesophageal reflux disease: Pathophysiology, diagnosis, and treatment. Gastroenterol Nurs 2019;42:20-8. doi: 10.1097/SGA.0000000000000359.

6. Menezes MA, Herbella FAM. Pathophysiology of Gastroesophageal Reflux Disease. World J Surg 2017;41:1666-71. doi: 10.1007/s00268-017-3952-4.

7. Wang D, Patel A, Mello M, Shriver A, Gyawali CP. Esophagogastric junction contractile integral (EGJ-CI) quantifies changes in EGJ barrier function with surgical intervention. Neurogastroenterol Motil 2016;28:639-46. doi: $10.1111 / \mathrm{nmo} .12757$.

8. Herbella FA, Patti MG. Gastroesophageal reflux disease: From pathophysiology to treatment. World J Gastroenterol 2010;16:3745-9. doi: 10.3748/wjg.v16.i30.3745.

9. Vaezi MF, Yang YX, Howden CW. Complications of proton pump inhibitor therapy. Gastroenterology 2017;153:35-48. doi: 10.1053/j.gastro.2017.04.047.

10. Yadlapati R, Vaezi MF, Vela MF, Spechler SJ, Shaheen NJ, Richter J, et al. Management options for patients with GERD and persistent symptoms on proton pump inhibitors: recommendations from an expert panel. Am J Gastroenterol 2018;113:980-6. doi: 10.1038/s41395-018-0045-4.

11. Hopkins J, Switzer NJ, Karmali S. Update on novel endoscopic therapies to treat gastroesophageal reflux disease: a review. World $J$ Gastrointest Endosc 2015;7:1039-44. doi: 10.4253/wjge.v7.i11.1039.

12. Yang XJ, Jiang HM, Hou XH, Song J. Anxiety and depression in patients with gastroesophageal reflux disease and their effect on quality of life. World J Gastroenterol 2015;21:4302-9. doi: 10.3748/wjg.v21.i14.4302.

13. Ong AML, Chua LTT, Khor CJL, Asokkumar R, Wang YT. Diaphragmatic breathing reduces belching and proton pump inhibitor refractory gastroesophageal reflux symptoms. Clin Gastroenterol Hepatol 2018;16:407-16. e2. doi: 10.1016/j.cgh.2017.10.038.

14. Herregods TV, van Hoeij FB, Oors JM, Bredenoord AJ, Smout AJ. Effect of Running on Gastroesophageal Reflux and Reflux Mechanisms. Am J Gastroenterol 2016;111:940-6. doi: 10.1038/ajg.2016.122.

15. Bilski J, Mazur-Bialy A, Magierowski M, Kwiecien S, Wojcik D, Ptak-Belowska A, et al. Exploiting Significance of Physical Exercise in Prevention of Gastrointestinal Disorders. Curr Pharm Des 2018;24:1916-25. doi: 10.2 174/1381612824666180522103759.

16. Djärv T, Wikman A, Nordenstedt H, Johar A, Lagergren J, Lagergren P. Physical activity, obesity and gastroesophageal reflux disease in the general population. World J Gastroenterol 2012;18:3710-4. doi: 10.3748/ wjg.v18.i28.3710. 
17. Mendes-Filho AM, Moraes-Filho JPP, Nasi A, Eisig JN, Rodrigues TN, Barbutti RC, et al. Influence of exercise testing in gastroesophageal reflux in patients with gastroesophageal reflux disease. ABCD Arquivos Brasileiros de Cirurgia Digestiva (São Paulo). 2014;27:3-8. doi: 10.1590/s010267202014000100002.

18. Kahrilas PJ. Medical management of gastroesophageal reflux disease in adults. In: Post TW, editor. UpToDate. Waltham, MA; 2015 [cited November 3, 2015]. Available at: http://www.uptodate.com/contents/ medical-management-of-gastroesophageal-reflux-disease-inadults

19. Spechler S, Castell D. Classification of oesophageal motility abnormalities. Gut 2001;49:145-51. doi: 10.1136/ gut.49.1.145.

20. Tofangchiha S, Razjouyan H, Nasseri-Moghaddam S. Quality of life in reflux and dyspepsia (QOLRAD) questionnaire in Iranian patients with GERD: A validation study. Middle East J Dig Dis 2010;2:84-90.

21. Department of Health and Human Services. 2008 Physical Activity Guidelines for Americans [Internet]. [cited 2008 Mar 4]. Available from: http://www.health.gov/ paguidelines/pdf/paguide.pdf.

22. Akyuz F, Mutluay Soyer O. Which diseases are risk factors for developing gastroesophageal reflux disease. Turk J Gastroenterol 2017;28:S44-S7. doi: 10.5152/ tjg.2017.12.

23. Mannino DM. COPD: epidemiology, prevalence, morbidity and mortality, and disease heterogeneity. Chest 2002;121:121S-6S. doi: 10.1378/chest.121.5 suppl.121s.

24. Eherer A, Netolitzky F, Högenauer C, Puschnig G, Hinterleitner T, Scheidl S, et al. Positive effect of abdominal breathing exercise on gastroesophageal reflux disease: a randomized, controlled study. Am J Gastroenterol 2012;107:372-8. doi: 10.1038/ajg.2011.420.

25. Roman S, Mion F. Refractory GERD, beyond proton pump inhibitors. Curr Opin Pharmacol 2018;43:99103. doi: 10.1016/j.coph.2018.09.001.

26. Carvalho de Miranda Chaves R, Suesada M, Polisel F, de Sa CC, Navarro-Rodriguez T. Respiratory physiotherapy can increase lower esophageal sphincter pressure in GERD patients. Respir Med 2012;106:1794-9. doi: 10.1016/j.rmed.2012.08.023.

27. Aanen MC, Weusten BL, Numans ME, de Wit NJ, Samsom M, Smout AJ. Effect of proton-pump inhibitor treatment on symptoms and quality of life in GERD patients depends on the symptom-reflux association. $J$ Clin Gastroenterol 2008;42:441-7. doi: 10.1097/ MCG.0b013e318074dd62.

28. Herregods TV, Van Hoeij FB, Oors JM, Bredenoord AJ, Smout AJ. Effect of running on gastroesophageal reflux and reflux mechanisms. Am $J$ Gastroenterol 2016;111:940-6. doi: 10.1038/ajg.2016.122.

29. Shohani M, Mohammadnejad S, Khorshidi A, Kiani SM. Effectiveness of aerobic exercise on dimensions of quality of life in elderly females. Journal of Nursing and Midwifery Sciences 2019;6:112-7. doi: 10.4103/ JNMS.JNMS_9_19. 